\title{
Academia à beira de um ataque de nervos: por uma ética nas relações sociais
}

\author{
Prof. Dr. HÉlio ARThur Reis IrigaraY ${ }^{1}$ \\ PROF. DR. FABRICIO STOCKER ${ }^{2}$ \\ 1 Fundação Getulio Vargas (FGV EBAPE) / Escola Brasileira de AdMinistração Pública e de EMpresas, Rio de JANEIRO - RJ, BRASIL \\ 2 Fundação Getulio VARgas (FGV) / CADERnOS EBAPE.BR, RIO DE JANEIRO - RJ, BRASIL
}

Na filosofia clássica, a ética não se limitava a questões morais, hábitos e costumes socialmente aceitos e valorizados, e sim a um padrão de comportamento, tanto na vida privada quanto na pública, cujo objetivo era encontrar o melhor modo de viver e conviver (Spinoza, 2020). Então, qual seria a distinção entre ética e moral?

A rigor, a principal diferença reside no fato de a ética estar relacionada à dimensão do dever e a moral, à da felicidade (Comte-Sponville \& Ferry, 1998), ou seja, ética é a perspectiva da vida boa, com outrem e para outrem, em instituições justas (Ricouer, 1990).

Por que hoje em dia, porém, há predileção por usar mais a palavra "ética", em detrimento de "moral"?

Spitz argumenta que o protagonismo ao qual o primeiro termo foi alçado esconde a intenção de "aliviar o inextricável embaraço daqueles que desejariam falar de moral sem ousar pronunciar esta palavra" (Spitz, 1995, p. 149). Talvez por isso, no senso comum, ética venha sendo interpretada como sinônimo de moral (Lévy-Bruhl, 1971), um instrumento que, por meio de valores socialmente constituídos, legitima valores, princípios e regras (Kant, 1985).

Em geral, ela é apreendida como antônimo de corrupção, atos de violência, incivilidades ou comportamentos que lesam outros indivíduos ou a sociedade como um todo (La Taille, Souza \& Vizioli, 2004). Essas interpretações mundanas explicam por que se ouve tanto falar de ética na política (Bobbio, 1997), na mídia (Baggio, 2011) ou corporativa (Cherman \& Tomei, 2005). No último caso, em especial, as empresas têm se debruçado sobre essa questão em seus discursos e promessas de serem socialmente responsável, bem como se engajarem em políticas e práticas de ESG (Environment, Social and Governance).

Assim, testemunhamos a concretização do "noivado entre a ética e o business" (Lipovetsky, 1992, p. 313), o que não significa que seja um relacionamento real, monogâmico, transparente, ou que resultará em casamento.

Em paralelo, na academia, essa discussão tem sido conduzida intramuros, em comitês e comissões de ética focados nas questões da ética nas pesquisas - fundamentalmente, na prática recorrente de cópia ilegal de textos, gráficos e ideias (Gasparyan, Nurmashe \& Voronov, 2016), ou nos procedimentos contemplados nos projetos que envolvem seres humanos (Santos, 2020).

Mais do que isso, entendemos que nós, acadêmicos e pesquisadores, devemos pautar as atividades no nosso papel social, ou seja, não podemos ser conduzidos por um pragmatismo pedestre ou uma instrumentalidade, o que revela vaidade e indiferença moral. Devemos apresentar uma série de qualidades morais - honestidade intelectual, desinteresse pessoal, defesa da verdade e crítica à falsidade -, cuja posse garanta uma melhor realização do objetivo fundamental que norteia nossa atividade (Vásquez, 1986). Essas qualidades morais também devem permear as relações sociais no ambiente acadêmico.

Ao longo de nossa vida profissional, interagimos com alunos, orientandos e pares; participamos de reuniões de colegiado e congressos; submetemos artigos; avaliamos e somos avaliados. Assim, a academia é idealizada como um lócus imaculado, no qual pessoas sábias, cultas e educadas criam e compartilham saberes, trocam ideias, sempre de maneira respeitosa. Mas não é isso que sempre acontece. Fazemos, então, um convite para refletirmos juntos sobre o ambiente acadêmico que herdamos, (co)criamos, e sobre as práticas às vezes deselegantes, perversas, que reproduzimos. 
Como editores, ouvimos queixas de colegas sobre terem tido artigos rejeitados para publicação quando tais textos haviam sido indicados a prêmio em congresso da área, ou, ainda, de eventual postura ríspida de algum parecerista. Nessas horas, não podemos esquecer que somos a própria academia, ora autores, ora avaliadores. Quando imbuídos nesse segundo papel, como avaliamos nossos pares? Quando redigimos nossos pareceres, somos educados e cuidadosos como queremos que sejam conosco? Parece que nosso ego não nos permite fazer tal reflexão.

É muito triste reconhecer que, de fato, ainda que seja raro, deparamos com avaliações superficiais ou, pior, grosseiras. Cabe deixar aqui registrado que isso não é um privilégio nosso. Como autores, já recebemos avaliações desse tipo de colegas estrangeiros.

Avaliar um artigo é contribuir para o avanço da discussão do campo, por isso nosso parecer deve ser detalhado. Se criticamos, devemos propor caminhos para que o trabalho seja aprimorado. Não é nosso papel questionar as premissas ontológicas dos autores, por mais que não compartilhemos delas. A nós, cabe avaliar se há um encadeamento lógico das ideias, se o marco teórico foi bem construído e não se limitou a um mero name-dropping. Os procedimentos de entrada e saída do campo, a coleta e o tratamento de dados estão bem descritos? Os resultados da pesquisa foram apresentados e discutidos? Acima de tudo, é preciso avaliar se se trata de um trabalho empírico ou de um ensaio teórico. Quais são as efetivas contribuições e implicações do estudo?

Esses comportamentos nocivos não se limitam a pareceres anônimos. Aparentemente, a academia está à beira de um ataque de nervos. E não podemos culpar a pandemia, pois não é um fenômeno recente.

Em congressos e conferências, já testemunhamos acadêmicos proferirem comentários e piadas de cunho misógino e homofóbico, agredir e ser sarcástico com seus pares, sem nenhum esboço de reação ou protesto por parte dos intelectuais presentes. Às vezes, o mesmo ocorre em discussões, debates e painéis, os quais, teoricamente, seriam um espaço para construirmos conhecimentos, mas que se tornaram palco de ataques pessoais, rispidez, egocentrismo e disputas políticas.

Comportamentos similares, práticas de assédio moral e sexual, também são relatados dentro das instituições de ensino. Mas se engana quem pensa que essa agressividade desmedida se limita a espaços físicos; ela invade as redes sociais e os grupos de WhatsApp. De modo assustador, a "elite intelectual do país" não demonstra o menor respeito pelos pares e por sua audiência; ela ataca, xinga e desmerece pesquisas em público.

Lamentavelmente, parece-nos que a academia está mais próxima de um octógono do que imaginávamos. Mas sempre é hora de nos reinventarmos. Assim, fica o convite para (re)inserirmos a virtude, de acordo com o senso aristotélico, nas nossas relações humanas. Com esse espírito deveras acadêmico, convido todos a refletir sobre as contribuições que os artigos desta terceira edição de 2021 dos Cadernos EBAPE.BR nos trazem.

O primeiro, "Estado de bem-estar social no Brasil: uma revisão ou a crise e o fim do 'espírito de Dunquerque", escrito por Claudio Gurgel e Agatha Justen, retoma o debate sobre o estado de bem-estar social no Brasil, visando verificar em que medida o capitalismo brasileiro e seu Estado integraram o esforço de reforma social que, em plano mundial, se realizou após a Segunda Guerra.

Já Daniele Silva Rodrigues, Felipe Rodrigues Cruz, Jacqueline Veneroso Alves da Cunha e João Estevão Barbosa Neto buscam, em "Irregularidades na execução dos recursos públicos destinados ao combate do Aedes aegypti nos estados brasileiros: análise do perfil das justificativas apresentadas pelos gestores à luz da teoria da atribuição", identificar as justificativas apresentadas pelos gestores estaduais e discutir seus vieses autosservidores sobre irregularidades observadas na utilização de recursos federais.

O terceiro artigo, "Fatores institucionais, interorganizacionais e financeiros em parques tecnológicos: um estudo sob a ótica da governança colaborativa", escrito por Lindsay Teixeira Sant'Anna, Dany Flávio Tonelli, Teresa Cristina Monteiro Martins, João Paulo Nascimento da Silva e Luiz Marcelo Antonialli, teve por objetivo investigar o nível de importância atribuído pelos atores envolvidos, nos parques tecnológicos em operação no Brasil, aos elementos fundamentais dos arranjos colaborativos, bem como verificar se estes estão presentes nas práticas cotidianas nos parques.

Por sua vez, Rodrigo Tavares de Souza Barreto e James Batista Vieira, em "Os programas de integridade pública no Brasil: indicadores e desafios", descrevem os programas de integridade implementados pela administração pública direta brasileira, com o objetivo de comparar suas práticas com o regime internacional anticorrupção. 
Visando analisar a relação de intensificação, afastamentos do trabalho e adoecimento dos trabalhadores nos frigoríficos de Mato Grosso do Sul, à luz do materialismo histórico, Gustavo Henrique Petean, Elcio Gustavo Benini e Gabriel Gualhanone Nemirosvky nos brindam com "Trabalho intensificado e afastamento do trabalho: uma análise nos frigoríficos no estado de Mato Grosso do Sul".

Em "Da manufatura moderna à grande indústria: delimitação empírica da mudança técnica no setor de autoveículos no Brasil (1996-2017)", Elcemir Paço Cunha, Lara Nora Portugal Penna e Leandro Theodoro Guedes delimitam, empiricamente, a inflexão do princípio na base técnica para o setor de autoveículos brasileiro, demarcando o período com maior probabilidade de ocorrência da transição entre manufatura moderna e grande indústria.

Wagner Ragi Curi Filho e Thomaz Wood Junior, por sua vez, em "Avaliação do impacto das universidades em suas comunidades", exploram o papel das universidades e seu impacto sobre as comunidades nas quais estão instaladas, oferecendo, ao fim, um modelo de avaliação de impacto.

As mudanças na governança corporativa associadas a ciclo de vida das empresas, maturidade do negócio, estrutura de propriedade, relações societárias e outras configurações de governança são objetos de estudo de Fabricio Bomtempo Oliveira e Joaquim Rubens Fontes Filho em "Mudanças nas configurações de governança corporativa e relações de agência: uma análise longitudinal em empresa de capital fechado".

Em "Nostalgia como prática? Relendo a pesquisa sobre nostalgia no campo do marketing", Flávio Medeiros Henriques e Maribel Carvalho Suarez refletem e propõem novas possibilidades de investigação do fenômeno da nostalgia no campo do marketing com base nas teorias da prática.

Arlindo Carvalho Rocha, Paula Chies Schommer, Emiliana Debetir e Daniel Moraes Pinheiro, em "Elementos estruturantes para a realização da coprodução do bem público: uma visão integrativa", discutem a coprodução de bens e serviços público sob uma visão integrativa, partindo da proposição de transparência, informação, confiança, participação e accountability.

O ensaio teórico "Contribuições de Deleuze e Guattari para uma perspectiva rizomática das organizações", escrito por Eline Gomes de Oliveira Zioli, Elisa Yoshie Ichikawa e Luciano Mendes, destaca uma multiplicidade de formas de pensar a organização, expressando e não negando a potência que a constitui, buscando dar continuidade aos esforços teóricos que se propõem a superar a construção da teorização organizacional marcada pelo funcionalismo, característico da organização moderna e que dificulta a proliferação de novas perspectivas de estudo.

"Ranking de transparência ativa de municípios do estado de Minas Gerais: avaliação à luz da Lei de Acesso à Informação", escrito por Josias Fernandes Alves, Adílio Renê Almeida Miranda, Marco Antonio Carvalho Teixeira e Paulo Roberto Rodrigues de Souza, é um artigo cujo objetivo é avaliar os portais eletrônicos de transparência das 13 regiões geográficas do estado de Minas Gerais.

Por sua vez, Marcos Roberto Nóbrega e Bruno Felix discutem as táticas usadas pelos expatriados para gerenciar a interface entre os domínios "trabalho" e "domicílio" em "Gerenciando os limites trabalho-lar: um estudo com expatriados".

Em “A ontologia pós-estruturalista sobre liderança: identidade e materialidade em evidência”, Eloisio Moulin de Souza realiza uma análise crítica do mainstream sobre liderança, tendo como lente de análise a ontologia pós-estruturalista sobre o tema.

Apresentamos também o artigo convidado "Deliberando ou protelando por justiça? Dinâmicas de remediação corporativa e resistência às vítimas pelas lentes do parentalismo: o caso da Fundação Renova no Brasil" (somente em português) de Rajiv Maher, publicado originalmente no Journal of Business Ethics, que apresenta uma rica contribuição empírica e teórica ao revelar doze tensões dialéticas das tentativas da Fundação Renova em remediar as injustiças causadas as vítimas do colapso da barragem de Fundão.

Finalizamos esta edição com a resenha bibliográfica "Para além do senso comum: 'Contra as eleições: o caso da democracia”", escrita por Tracy Jeanel St. Louis e Airton Cardoso Cançado.

Boa leitura a todos!

PRof. Dr. HÉLIo ARTHUR Reis IRIGARAY

EDITOR-CHEFE

PROF. DR. FABRICIO StOKER

EDITOR ADJUNTO 


\section{REFERÊNCIAS}

Baggio, M. A. (2011). Ética e mídia. Revista Médica de Minas Gerais, 21(2), 229-237.

Bobbio, N. (1997). El filósofo y la política. Cidade do México, MX: Fondo de Cultura Económica.

Cherman, A., \& Tomei, P. (2005). Códigos de ética corporativa e a tomada de decisão ética: instrumentos de gestão e orientação de valores organizacionais? RAC - Revista de Administração Contemporânea, 9(3), 99-120.

Comte-Sponville, A., \& Ferry, L. (1998). La sagesse des modernes. Paris, France: Lafont.

Gasparyan, A., Nurmashev, B., \& Voronov, A. (2016). The pressure to publish more and the scope of predatory publishing activities. Journal of Korean Medicinal Science, 31(12), 1874-1878.

Kant, I. (1985). Crítica da razão prática. Petrópolis, RJ: Editora Vozes.
La Taille, Y., Souza, L., \& Vizioli, L. (2004). Ética e educação: uma revisão da literatura educacional de 1990 a 2003. Educação e Pesquisa, 30(1), 91-108.

Lévy-Bruhl, L. (1971). La morale et la science des moeurs. Paris, France: PUF.

Lipovetsky, G. (1992). Le crépuscule du devoir. Paris, France: Gallimard.

Ricoeur, P. (1990). Soi-même comme un autre. Paris, France: Gallimard.

Santos, R. E. (2020). Pequena discussão sobre o social e o ético na academia. Revista Mosaicum, 6(11), 32-40.

Spinoza, B. (2020). Ética. Amazon: e-book. São Paulo, SP: Edusp. Spitz, B. (1995). La morale à zéro. Paris, France: Seuil.

Vásquez, A. (1986). Ética (9a ed.). São Paulo, SP: Civilização Brasileira. 